\title{
Occidental College
}

From the SelectedWorks of Shana Goffredi

July 30, 2004

\section{Osedax: Bone-Eating Marine Worms with Dwarf Males}

G W Rouse

Shana K Goffredi

R C Vrijenhoek 
octadecanoid-dependent transcriptional responses (fig. S3) (17). Of the 240 N. attenuata genes spotted on the microarray, 54 genes showed significantly increased LOX3dependent transcript accumulation after $\mathrm{Em}$ poasca damage and 50 showed decreased accumulation (table S3). A series of defenserelated genes, such as trypsin proteinase inhibitor (TPI) and threonine deaminase, had increased expression levels, whereas others, such as xyloglucan endotransglucosylase/ hydrolase or GAL83 and many of the photosynthesis-related genes (e.g., small subunit of ribulose bisphosphate carboxylase), were down-regulated in response to $\mathrm{Em}$ poasca attack and showed little if any regulation in as-lox plants (table S3). These results suggest that a complex LOX3dependent regulation of primary and secondary metabolism in $N$. attenuata mediates resistance to the piercing-sucking Empoasca leafhoppers. The fact that octadecanoid signaling plays a role in plant defense against both piercing-sucking and leaf-chewing insects suggests a common response to attack from members of these two feeding guilds. Moreover, LOX3-dependent octadecanoids may play a direct role in host-plant selection by enabling herbivores to differentiate between plants with and without intact JA signaling, as shown in experiments with the corn earworm, Helicoverpa zea. This generalist herbivore uses induced JA and salicylate to activate four of its cytochrome P450 genes that are associated with detoxification either before or concomitantly with the biosynthesis of allelochemicals (29).

In addition to $M$. sexta, which was affected by LOX3-mediated plant resistance traits, we found a novel leaf-chewing herbivore on $N$. attenuata, the leaf beetle $D i$ abrotica undecimpunctata tenella Le Conte (fig. S2C). It often feeds on D. wrightii and Cucurbita foetidissima flowers in the study area and was observed on $N$. attenuata plants exclusively in this study and only on as-lox plants. To test whether or not this clear preference in the field is caused by the decreased expression of LOX3, we allowed the beetles to choose between WT and aslox plants. The choice experiment revealed a clear preference for as-lox plants compared to WT plants (paired Student's $t$ test, $t=-4.050, P=0.003$ ) (Fig. 4).

Our results show that the LOX3-mediated inducibility of plants is crucial for the oviposition decision and for the opportunistic host selection behavior of Empoasca sp. and D. undecimpunctata, and thereby defines host breadth. Therefore, host selection seems determined not only by the plant's constitutively expressed chemical phenotype and external mortality factors (predation pressure, abiotic stress) (30) but also by the plant's ability to induce responses to herbivory. The additional finding that induced responses to herbivory influence the distribution of herbivory within a plant community points to the value of genetically silenced plants in ecological research. An understanding of the ecological interactions that occur in nature is essential for sustainable agriculture.

References and Notes

1. S. S. Duffey, M. J. Stout, Arch. Insect Biochem. Physiol. 32, 3 (1996).

2. C. M. De Moraes, W. J. Lewis, P. W. Pare, H. T. Alborn, J. H. Tumlinson, Nature 393, 570 (1998).

3. M. Dicke, J. J. A. van Loon, Entomol. Exp. Appl. 97, 237 (2000).

4. J. S. Thaler, M. J. Stout, R. Karban, S. S. Duffey, Ecol. Entomol. 26, 312 (2001).

5. A. Kessler, I. T. Baldwin, Science 291, 2141 (2001).

6. T. C. J. Turlings, J. H. Tumlinson, W. J. Lewis, Science 250, 1251 (1990).

7. R. Karban, I. T. Baldwin, Induced Responses to Herbivory (Univ. of Chicago Press, Chicago, IL, 1997).

8. A. A. Agrawal, Science 294, 321 (2001).

9. C. A. Preston, I. T. Baldwin, Ecology 80, 481 (1999).

10. A. Kessler, I. T. Baldwin, Plant J. 38, 639 (2004).

11. R. Halitschke, U. Schittko, G. Pohnert, W. Boland, I. T. Baldwin, Plant Physiol. 125, 711 (2001).

12. E. Blee, Trends Plant Sci. 7, 315 (2002).

13. R. A. Creelman, J. E. Mullet, Annu. Rev. Plant Physiol. Plant Mol. Biol. 48, 355 (1997).

14. J. Bergelson, C. B. Purrington, C. J. Palm, J. C. LopezGutierrez, Proc. R. Soc. London B Biol. Sci. 263, 1659 (1996).

15. J. Royo et al., Proc. Natl. Acad. Sci. U.S.A. 96, 1146 (1999).

16. J. A. Zavala, A. G. Patankar, K. Gase, I. T. Baldwin, Proc. Natl. Acad. Sci. U.S.A. 101, 1607 (2004).

17. Materials and methods are available as supporting material on Science Online.

18. R. Halitschke, I. T. Baldwin, Plant J. 36, 794 (2003).

19. L. Li et al., Plant Cell 16, 126 (2004).

20. R. Halitschke, M. Keinanen, J. Ziegler, I. T. Baldwin, Plant J., in press.
21. D. F. Hildebrand, G. C. Brown, D. M. Jackson, T. R. Hamilton-Kemp, J. Chem. Ecol. 19, 1875 (1993).

22. N. J. Bate, S. J. Rothstein, Plant J. 16, 561 (1998).

23. G. Arimura, R. Ozawa, J. Horiuchi, T. Nishioka, J. Takabayashi, Biochem. Syst. Ecol. 29, 1049 (2001).

24. J. H. Park et al., Plant J. 31, 1 (2002).

25. A. Stinzi, J. Browse, Proc. Natl. Acad. Sci. U.S.A. 97, 10625 (2000).

26. As plants began to elongate and produce flowers, they were examined daily; all flowers were removed before opening and anthesis to meet the performance standards determined in the Code of Federal Regulations [7CFR340.3(c)] for the Introduction of Organisms Altered or Produced through Genetic Engineering. Consequently, direct fitness measures were unattainable in these experiments.

27. M. Kunert, A. Biedermann, T. Koch, W. Boland, J. Sep. Sci. 25, 677 (2002).

28. Probably belonging to the species E. fabae (Harris, 1841), which is widely known as a pest on alfalfa in the United States.

29. X. C. Li, M. A. Schuler, M. R. Berenbaum, Nature 419 , 712 (2002).

30. E. Bernays, M. Graham, Ecology 69, 886 (1988).

31. Supported by the Max-Planck-Gesellschaft and Deutsche Forschungsgemeinschaft (BA-2132/1-1). We thank E. Wheeler, E. Pichersky, D. Heckel, J. Gershenzon, M. Heil, and H. Vogel for helpful comments; R. Baumann, P. Freytag, and H. Nickel for assistance with species determination; and Brigham Young University for use of Lytle Preserve as a field station; L. Rausing for helping us promote the discussion of the scientific value of transformed plants; and J. White and the Animal and Plant Health Inspection Service personnel for facilitating their safe use in nature.

\section{Supporting Online Material}

www.sciencemag.org/cgi/content/full/1096931/DC1

Materials and Methods

Figs. $\mathrm{S} 1$ to $\mathrm{S} 3$

Tables S1 to S3

References

18 February 2004; accepted 7 June 2004

Published online 1 July 2004;

10.1126/science. 1096931

Include this information when citing this paper.

\title{
Osedax: Bone-Eating Marine Worms with Dwarf Males
}

\author{
G. W. Rouse, ${ }^{1,2 *}$ S. K. Goffredi, ${ }^{3 *}$ R. C. Vrijenhoek ${ }^{3} \dagger$
}

\begin{abstract}
We describe a new genus, Osedax, and two new species of annelids with females that consume the bones of dead whales via ramifying roots. Molecular and morphological evidence revealed that Osedax belongs to the Siboglinidae, which includes pogonophoran and vestimentiferan worms from deep-sea vents, seeps, and anoxic basins. Osedax has skewed sex ratios with numerous dwarf (paedomorphic) males that live in the tubes of females. DNA sequences reveal that the two Osedax species diverged about 42 million years ago and currently maintain large populations ranging from $10^{5}$ to $10^{6}$ adult females.
\end{abstract}

Deep-sea exploration continues to reveal biological novelties ( 1 ) such as whale fall communities (2). Here, we describe remarkable polychaete annelids, Osedax gen. nov. (nov.), discovered in January 2002 on the bones of a gray whale carcass at $2891 \mathrm{~m}$ depth in Monterey Bay, California (3). Their conspicuous red plumes extended from most exposed portions of the whale bones (Figs. 1A and 2A). Colonies of these worms comprised two species, Osedax rubiplumus sp. nov. and $O$. frankpressi sp. nov., that we describe along with the new genus. Nucleotide sequence analysis revealed that the two Osedax species differed by $17.28 \pm 0.21 \%(\bar{x} \pm \mathrm{SD})$ for mitochondrial COI, by $7.63 \pm 0.46 \%$ for mitochondrial 16S rRNA, and by $4.09 \pm 0.04 \%$ for nuclear 18S rRNA (4). On the basis of a molecular clock calibrated for COI in deepsea annelids (5), O. rubiplumus and $O$. frankpressi diverged about 42 million years ago (Ma) (4), in the late Eocene, when their 
ancestor may have exploited the bones of archeocete whales such as Basilosaurus (6). Phylogenetic analysis (Fig. 3) placed Osedax in the family Siboglinidae $(7,8)$, which includes frenulate and vestimentiferan tubeworms that also lack digestive systems $(9,10)$.

Unlike other siboglinids, female Osedax lack a discrete trophosome, the organ housing symbiotic bacteria in vestimentiferans and pogonophorans. Instead, Osedax possess a bulbous posterior ovisac covered by a sheath of green-colored tissue that branches into a vascularized "root" system and invades the bone marrow (Figs. 1, C and $\mathrm{H}$, and 2, C, D, and F). This branching root system is histologically distinct and not homologous with the singular chitinous root tube found in some Lamellibrachia vestimentiferans (11). Microscopic and molecular analyses (12) of this sheath revealed bacteriocytes (Fig. 1J) containing large rodshaped bacteria of the microbial order Oceanospirillales, known for heterotrophic degradation of complex organic compounds. Analyses of stable isotopes and fatty acids (12) revealed that the endosymbionts are responsible for the nutrition of this worm. This heterotrophic symbiosis differs markedly from the chemolithoautotrophic symbioses found in other deep-sea annelids and mollusks that rely on sulfide- or methane-oxidizing bacterial endosymbionts (13). This finding of an endosymbiosis involving heterotrophic degradation in Osedax suggests that the evolutionary history of bacterial symbioses among the Siboglinidae is more varied than previously suspected (14). Reliance on the bones of marine mammals, hydrocarbon degradation, and the unusual morphology of the symbiont-bearing ovisac and root system of these worms make this particular symbiotic association unique in the animal kingdom.

All Osedax visible to the eye were females that ranged from 0.2 to $0.5 \mathrm{~mm}$ in trunk width, suggesting ongoing recruitment. Females as small as $0.3 \mathrm{~mm}$ wide produced eggs (Figs. 1, $\mathrm{D}$ and $\mathrm{F}$, and $2 \mathrm{~F}$ ). The tubes of individual females contain numerous microscopic males (Figs. 1, K to O, and 2G) that were filled with developing sperm (Fig. 1N) and often contained yolk droplets (Fig. 2I). These paedomorphic males retain morphological traits typical of siboglinid trochophore larvae (15), including a ciliary band that appears to be a putative prototroch (Figs. 1L and 2I) and opisthosomal chaetae (Figs. $1 \mathrm{O}$ and $2 \mathrm{H}$ ). The tubes of larger females contained up to 111 males each, with a

${ }^{1}$ South Australian Museum, North Terrace, Adelaide SA 5000, Australia. ${ }^{2}$ Earth and Environmental Sciences, University of Adelaide, Adelaide SA 5005, Australia. 3Monterey Bay Aquarium Research Institute (MBARI), 7700 Sandholdt Road, Moss Landing, CA 95039, USA.

*These authors contributed equally to the work. †T whom correspondence should be addressed. Email: vrijen@mbari.org male-to-female sex ratio of $17: 1$. Females either accumulate males over time or attract more when larger, because the number of males is correlated $(r=0.899, P<0.01)$ with female size in O. rubiplumus (16). We hypothesize that sex may be environmentally determined in Osedax, with larvae settling on exposed bones maturing as females and those landing on females becoming males. Environmental sex determination is known in the echiuran Bonellia (17), now regarded as a polychaete (18).

Amounts of mitochondrial COI diversity $(\theta)$ suggest that the effective female population sizes $\left[N_{\mathrm{e}(\mathrm{f})}\right]$ range from $5 \times 10^{5}$ in $O$. rubiplumus to $9 \times 10^{5}$ in O. frankpressi.
These numbers are of the same magnitude as estimates of $N_{\mathrm{e}(\mathrm{f})}$ (range of $10^{5}$ to $10^{6} \mathrm{fe}$ males) inferred for deep-sea annelids (4) and consistent with estimates of $N_{\text {e(f) }}$ from other invertebrates (19). The large female population sizes estimated for these Osedax species suggest they are common on whale falls. These numbers also suggest that the frequency of whale falls has historically been great, which is consistent with estimates of large whale populations before modern whaling (2, 20). Their abundance suggests that these worms might play a substantial role in the cycling of large organic inputs into the surrounding deep-sea communities.

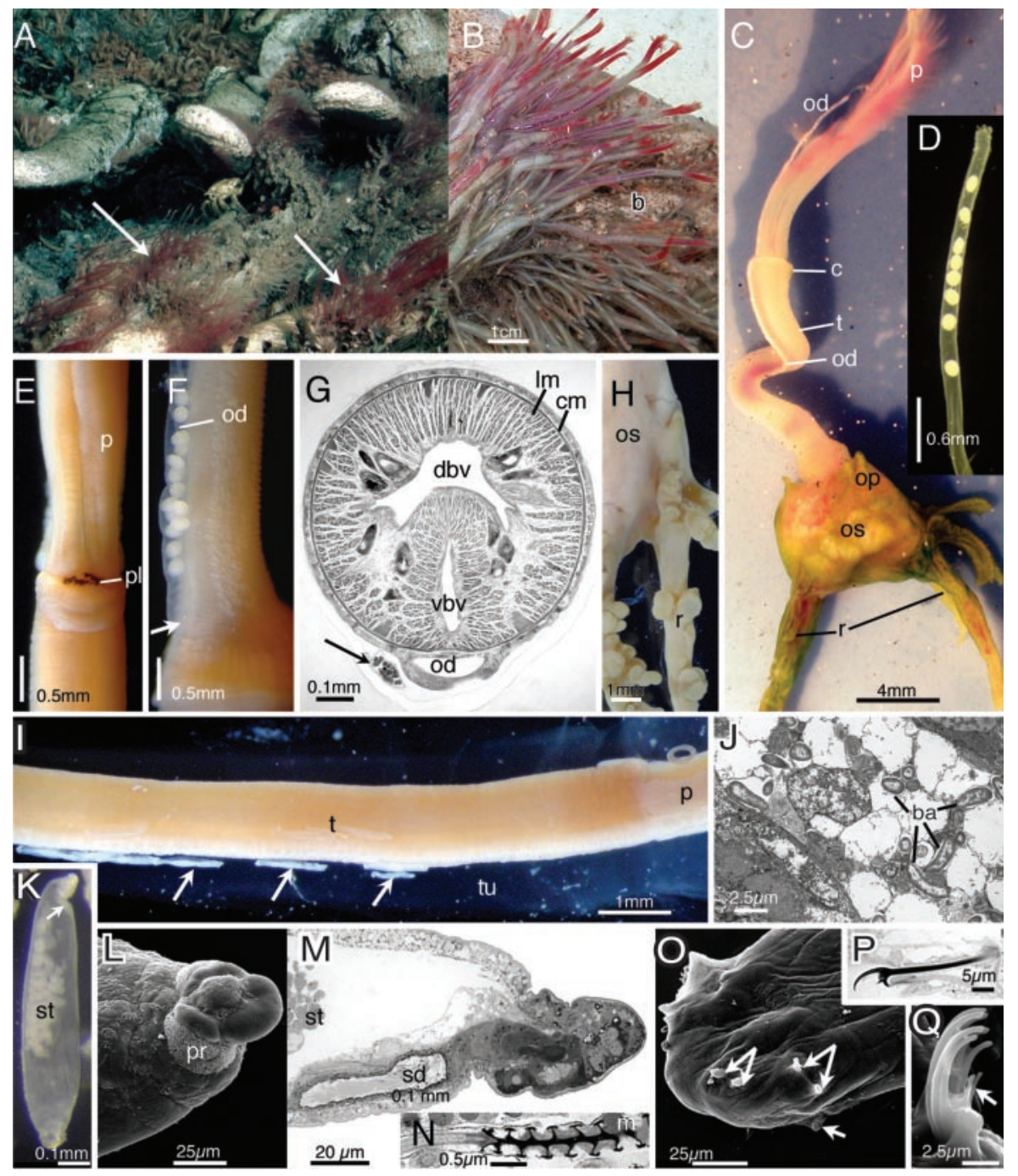

Fig. 1. O. rubiplumus. (A) Bones in situ with emergent worms (arrows). (B) Whale rib with female worms. (C) Female, tube removed, dissected from bone. (D) Anterior of oviduct with eggs. (E) Dorsal crown-trunk junction. (F) Lateral trunk base with oviduct emerging from ovisac (arrow). (G) Transverse section of anterior trunk. Male sits on oviduct (arrow). (H) Lateral ovisac and roots of holotype. (I) Dwarf males (arrows) in tube with female. (J) Transmission electron micrograph (TEM) of root tissue with bacteriocytes. (K) Dwarf male with sperm duct (arrow) and spermatids. (L) Scanning electron micrograph (SEM) of male anterior. (M) Longitudinal section (LS) through male anterior. (N) Longitudinal TEM section through posterior of sperm head. (O) SEM of posterior hooks (arrows) on male. (P) LS through hook. (Q) SEM of hook with subrostral teeth (arrow). b, bone; ba bacteria; c, collar; cm, circular muscle; dbv, dorsal blood vessel; od, oviduct; Im longitudinal muscle; m, male; op, ovisac projection; os, ovisac; p, palps; pl, plaques; pr, prototroch; r, roots; sd, sperm duct; st, spermatids; t, trunk; tu, tube; and vbv, ventral blood vessel. 
Systematic description. Annelida, Lamarck 1809; Canalipalpata, Rouse and Fauchald 1997; Siboglinidae Caullery, 1914. Osedax gen. nov. Diagnosis. Polychaete worms with females having a discrete red crown, contractile trunk, bulbous ovisac, and branching roots. Crown and trunk within transparent tube emergent from whale bone (Figs. 1, A and B, and 2, A to C). Crown composed of cylindrical oviduct (Figs. $1 \mathrm{D}$ and 2E) plus four pinnule-bearing palps (Figs. 1C and 2, D and E). No mouth or obvious gut. Cylindrical trunk composed mostly of longitudinal muscles and glands. Dorsal heart lies at anterior region of trunk; major dorsal and ventral blood vessels present (Fig. 1G). Oviduct parallels trunk surface into posterior ovisac (Figs. 1, C and $\mathrm{F}$ to $\mathrm{G}$, and $2 \mathrm{D}$ ) filled with numerous white oocytes. Ovisac enclosed by green sheath (Fig. 2F) composed of epidermis and bacteriocytes containing bacteria (Fig. 1J). Ovisac sheath continuous with variably branching posterior roots (Figs. 1, C and H, and 2D). Vascularized roots and ovisac (Fig. 2F). No chaetae or segmentation apparent in females. Paedomorphic males cluster around oviduct in female tubes (Figs. 1, I and K, and $2 \mathrm{G}$ ). Males with anterior prototroch (Figs. $1 \mathrm{~L}$ and $2 \mathrm{I}$ ) and posterior hooked chaetae (Figs. $1 \mathrm{O}$ and $2 \mathrm{H}$ ) arranged in two rows of four pairs (Fig. 1O). Hooks, lacking rostrum, comprise capitium with curved teeth over subrostral process (Figs. 1, P and Q, and 2H). Internally, males contain spermatids and sperm in anterior duct (Fig. 1, K and M, and 2I). Etymology. From Latin os, bone, and edax, devouring; gender masculine. Type species. Osedax rubiplumus sp. nov. by present designation.

Osedax rubiplumus sp. nov. Type material. (21) Monterey Bay, California, Tiburon dive $\mathrm{T} 486,36^{\circ} 36.8^{\prime} \mathrm{N}, 122^{\circ} 26.0^{\prime} \mathrm{W}, 2891 \mathrm{~m}$, 8 February 2002: holotype, mature adult female (CASIZ 170238); allotypes, 38 males from tube of holotype (CASIZ 170240); paratypes, 10 females and numerous males (CASIZ 170239), 10 females and numerous males (LACM-AHF POLY 02146), and 31 females and numerous males (SAM E3376). Diagnosis. Holotype, emergent body in cylindrical tube, walls $1 \mathrm{~mm}$ thick. Contracted crown plumes $2.1 \mathrm{~cm}$ long. Oviduct, filled with ellipsoid eggs (mean diameters $151 \mu \mathrm{m}$ by $121 \mu \mathrm{m}, n=30$ ). Oviduct extends between palps, $1.8 \mathrm{~cm}$ from trunk. Palps red in living worms, pinnules on outer margins. Collar with brown plaques dorsally (Fig. 1E). Trunk $3.8 \mathrm{~cm}$ long, $2 \mathrm{~mm}$ wide at collar. Ovisac, $8 \mathrm{~mm}$ by $4 \mathrm{~mm}$ by $0.3 \mathrm{~mm}$, with paired anterolateral projections (Fig. 1C) and four discrete roots posteriorly. Roots with spherical lobes (Fig. 1H). Allotypes 0.4- to 1.1-mm-long males. Putative prototroch incomplete (Fig. 1L). Posteriorly, 16 hooks with capitium teeth emergent; handles 18 to $23 \mu \mathrm{m}$ (Fig. 1P). Capitium with six to eight teeth; two smaller subrostrumal teeth (Fig. 1Q). Etymology. From Latin rubi, red, and pluma, feather.

Osedax frankpressi $\mathrm{sp}$. nov. Type material. (21) Monterey Bay, California, Tiburon dive T610, 36 36.8'N, 122²6.0'W, 2891 m, 7 August 2002: holotype, mature adult female
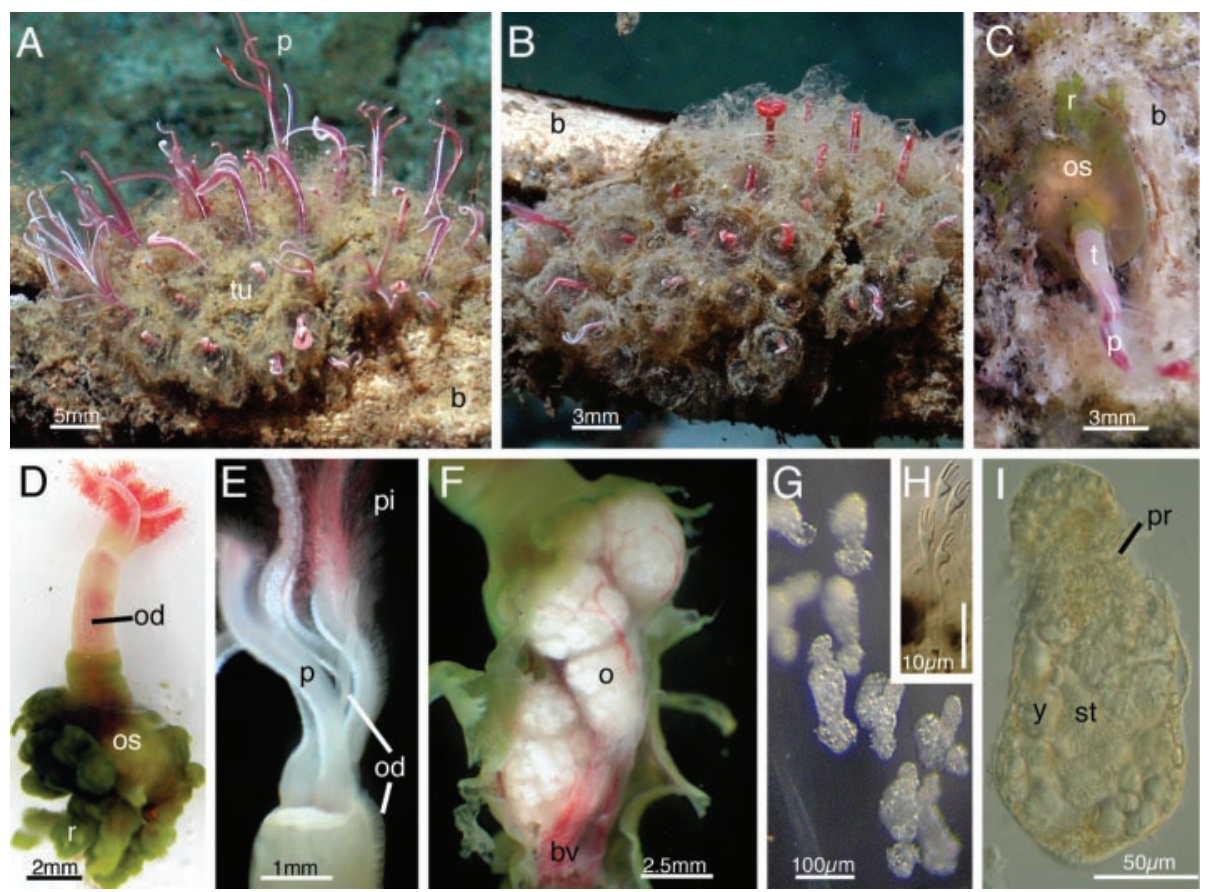

Fig. 2. O. frankpressi. (A) Whale rib in situ with emergent worms. (B) Retracted worms. (C) Female partly dissected from bone; note fluid-filled ovisac. (D) Female dissected from bone. (E) Crowntrunk junction. (F) Ovisac with green sheath cut to reveal ovary and blood vessels. (G) Dwarf males in female tube. (H) Male hooks. (I) Male showing prototroch, developing sperm, and yolk. bv, blood vessel; $y$, yolk; otherwise as for Fig. 1.
(CASIZ 170235); allotypes, 80 males from tube of holotype (CASIZ 170237); paratypes, three females (CASIZ 170236), three females (LACM-AHF POLY 02147), three females (SAM E3377). Diagnosis. Holotype, emergent body in gelatinous hemispherical tube, $7-\mathrm{mm}$ diameter. Contracted crown plumes $0.95 \mathrm{~cm}$ long. Oviduct filled with ellipsoid eggs (mean diameters $146 \mu \mathrm{m}$ by $117 \mu \mathrm{m} ; n=$ 15), Oviduct convoluted upon contraction, extending between palps, $3 \mathrm{~mm}$ from trunk (Fig. 2, D and E). Palps red with two longitudinal white stripes in living worms (Fig. 2A); pinnules on inner margins. Trunk 4.5 $\mathrm{mm}$ long, $0.9 \mathrm{~mm}$ wide, and marked by white thickened tissue at anterior (Fig. 2E). Green, bacteriocyte-filled sheath forms trunk-ovisac junction $1.2 \mathrm{~mm}$ long, $1 \mathrm{~mm}$ wide (Fig. 2D). Lobulate ovisac, $6.5 \mathrm{~mm}$ by $5 \mathrm{~mm}$ by $3 \mathrm{~mm}$ (Fig. 2F). Ovisac and roots inflated with clear fluid in situ in bone (Fig. 2C); fluid lost on extraction. Allotypes, 0.15- to 0.25-mm-long males (Fig. 2, G and I). Chaetae with hooks and handles 15 to 21 $\mu \mathrm{m}$ (Fig. 2H). Capitium with five teeth; no subrostral teeth (Fig. 2H). Etymology. In honor of Dr. Frank Press, former U.S. presidential science advisor, president of the U.S. National Academy of Sciences, and chair of the MBARI Board of Directors, for his distinguished service to science.

Remarks. Females of the two new species are easily distinguished by the lengths of their tubes and palp coloration. O. rubiplumus tubes have a uniform diameter and maintain shape when removed from the water, whereas $O$. frankpressi tubes are gelatinous and collapse in air. The white-striped $O$. frankpressi palps contrast with the uniform red palps of O. rubiplumus. Females of the two species differ in the

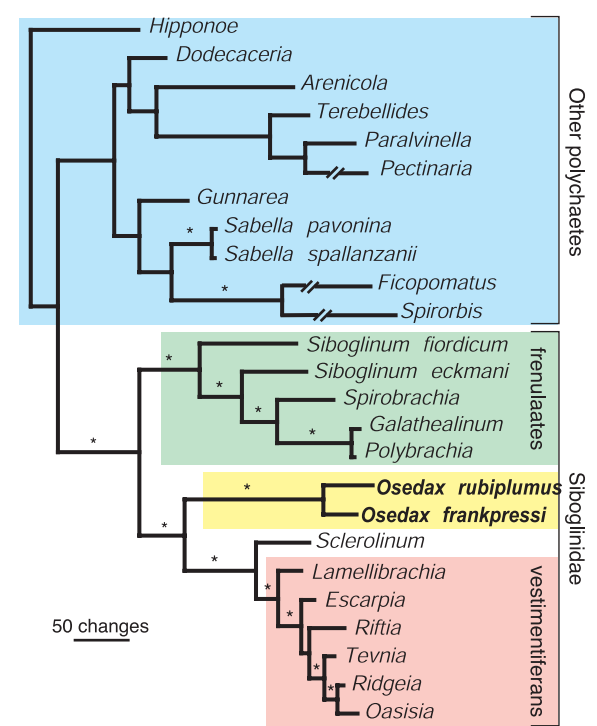

Fig. 3. Osedax as member of Siboglinidae. Bayesian analyses of 2088 molecular characters from combined $16 \mathrm{~S}$ and $18 \mathrm{~S}$ rDNA (22). Posterior probability values of $100 \%$ indicated by asterisks. 
trunk-ovisac junction, ovisac shape, and ramification of roots. Males of $O$. frankpressi are less than one-third the size of $O$. rubiplumus males. Male chaetae of $O$. rubiplumus have subrostral teeth and more capitium teeth.

References and Notes

1. C. L. Van Dover, C. R. German, K. G. Speer, L. M. Parson, R. C. Vrijenhoek, Science 295, 1253 (2002).

2. C. R. Smith, A. R. Baco, Oceanogr. Mar. Biol. Annu. Rev. 41, 311 (2003).

3. S. K. Goffredi, C. K. Paull, Fulton-Bennett, L. A. Hurtado, R. C. Vrijenhoek, Deep Sea Res. I, in press.

4. Details on materials and methods and GenBank accession numbers are available as supporting material on Science Online.

5. P. Chevaldonné, D. Jollivet, D. Desbruyères, R. A. Lutz, R. C. Vrijenhoek, Cah. Biol. Mar. 43, 367 (2002).

6. P. D. Gingerich, B. H. Smith, E. L. Simons, Science $\mathbf{2 4 9}$ 154 (1990).

7. K. M. Halanych, R. A. Feldman, R. C. Vrijenhoek, Biol. Bull. 201, 65 (2001)

8. G. W. Rouse, Zool. J. Linn. Soc. 132, 55 (2001).

9. E. C. Southward, in Microscopic Anatomy of Invertebrates, vol. 12 of Onychophora, Chilopoda and Lesser Protostomata, F. W. Harrison, M. E. Rice, Eds. (WileyLiss, New York, 1993), pp. 327-369.

10. M. L. Jones, Science 213, 333 (1981).

11. D. Julian, F. Gaill, E. Wood, A. Arp, C. Fisher, J. Exp. Biol. 202, 2245 (1999).

12. S. K. Goffredi et al., in preparation.

13. C. L. Van Dover, The Ecology of Deep-Sea Hydrothermal Vents (Princeton Univ. Press, Princeton, NJ 2000), p. 411.

14. A. Schulze, K. M. Halanych, Hydrobiologia 496, 199 (2003).

15. E. C. Southward, Hydrobiologia 402, V185 (1999).

16. Fifty-four female Osedax rubiplumus from a piece of rib obtained on Tiburon dive 486 were measured and assessed for spawning, and their tubes were checked for males. Details are available at (4).

17. J. Pilger, in Settlement and Metamorphosis of Marine Invertebrate Larvae, F.-S. Chia, M. E. Rice, Eds. (Elsevier, New York, 1978), pp. 103-112.

18. D. McHugh, Proc. Natl. Acad. Sci. U.S.A. 94, 8006 (1997).

19. M. Lynch, J. S. Conery, Science 302, 1401 (2003).

20. J. Roman, S. R. Palumbi, Science 301, 508 (2003).

21. Repositories of type specimens are as follows: CASIZ, California Academy of Sciences; LACM, Los Angeles County Museum; and SAM, South Australia Museum.

22. Phylogenetic analysis has its basis in $18 \mathrm{~S}$ and $16 \mathrm{~S}$ rDNA sequences. The amphinomid Hipponoe was chosen to root the tree. Additional polychaete sequences were obtained from GenBank. Ambiguously aligned sections of $18 \mathrm{~S}$ rDNA were excluded from the analysis. PAUP* $4.0 b 10$ (D. Swofford, Florida State University) was used for maximum parsimony analysis with characters equally weighted and gaps treated as missing data. Bootstrap values were estimated with the use of 1000 heuristic searches. Bayesian analysis used MrBayes v3.0B4 (J. Huelsenbeck, University of Rochester, NY) with partitions for stems and loops using RNA secondary structure prediction via GeneBee (L. Brodsky, Moscow State University, Russia). Likelihood models were chosen with the use of ModelTest 3.06 (D. Posada, Universidad de Vigo, Spain). Further details are available at (4).

23. Funding provided by the David and Lucile Packard Foundation, NSF (OCE9910799 and OCE0241613), and the South Australian Museum. Thanks to Tiburon pilots and Western Flyer crew for obtaining samples; J. Jones and R. Young for help with Bayesian analysis; R. Newbold and F. Pleijel for Latin advice; H. Schoppe, $\mathrm{K}$. Rogers, and Adelaide Microscopy for microscopy support, and V. Orphan, L. Jahnke, T. Embaye, and K. Turk (NASA Ames Research Center) for nutritional characterization of the worms.

Supporting Online Material

www.sciencemag.org/cgi/content/full/305/5684/668/DC Materials and Methods

Fig. S1

Tables S1 to S3

1 April 2004; accepted 29 June 2004

\title{
The Complete Genome Sequence of Propionibacterium Acnes, a Commensal of Human Skin
}

\author{
Holger Brüggemann, ${ }^{1 * \dagger}$ Anke Henne, ${ }^{1}$ Frank Hoster, ${ }^{1}$ \\ Heiko Liesegang, ${ }^{1}$ Arnim Wiezer, ${ }^{1}$ Axel Strittmatter, ${ }^{1}$ \\ Sandra Hujer, ${ }^{2}$ Peter Dürre, ${ }^{2}$ Gerhard Gottschalk ${ }^{1} \dagger$
}

\begin{abstract}
Propionibacterium acnes is a major inhabitant of adult human skin, where it resides within sebaceous follicles, usually as a harmless commensal although it has been implicated in acne vulgaris formation. The entire genome sequence of this Gram-positive bacterium encodes 2333 putative genes and revealed numerous gene products involved in degrading host molecules, including sialidases, neuraminidases, endoglycoceramidases, lipases, and pore-forming factors. Surface-associated and other immunogenic factors have been identified, which might be involved in triggering acne inflammation and other $P$. acnesassociated diseases.
\end{abstract}

The details of the involvement of Propionibacterium acnes in acne- the most common skin disease, affecting up to $80 \%$ of all adolescents in the United States - are still obscure. Several mechanisms have been proposed to account for its role in the disease (1-5). First, damage to host tissues and cells might be accomplished by bacterial enzymes with degradative properties, such as lipases (2). Second, immunogenic factors of $P$. acnes such as surface determinants or heat shock proteins (HSPs) might trigger inflammation (4-6). Other diseases are also associated with $P$. acnes, including corneal ulcers; endocarditis; sarcoidosis; cholesterol gallstones; allergic alveolitis; pulmonary angitis; and synovitis, acne, pustulosis, hyperostosis, and osteitis (SAPHO) syndrome $(7,8)$. Its genome sequence may provide a basis for finding alternative targets in therapy for acne and other $P$. acnes-associated diseases.

The genome of $P$. acnes strain KPA171202 (no. DSM 16379) consists of a single circular chromosome of 2,560,265 base pairs $(9,10)$ (supporting online text and fig. S1). We predicted and annotated 2333 putative genes. The sequenced strain exhibited $100 \%$ identity on the $16 \mathrm{~S}$ ribosomal RNA level to several clinical $P$. acnes isolates, as well as to the wellstudied laboratory strain P-37. The main features of the genome sequence and comparative analyses are described in the supporting online material (supporting online text and fig. S2).

${ }^{1}$ Göttingen Genomics Laboratory, Institute of Microbiology and Genetics, Georg-August-University Göttingen, Grisebachstraße 8, 37077 Göttingen, Germany. ${ }^{2}$ Department of Microbiology and Biotechnology, University of Ulm, 89069 Ulm, Germany.

*Present address: Institut Pasteur, Laboratory of Genomics of Microbial Pathogens, 28 Rue du Dr. Roux, 75724 Paris, France.

$\dagger$ To whom correspondence should be addressed. Email: hbruegg@pasteur.fr (H.B.) and ggottsc@gwdg. de (G.G.)
The genome sequence offers insights into the traits that favor $P$. acnes as a ubiquitous commensal on human skin. Metabolic reconstruction reveals a capacity to cope with changing oxygen tensions, which confirms observations that strains of $P$. acnes can grow under microaerobic as well as anaerobic conditions. The genome sequence encodes all key components of oxidative phosphorylation that employs two terminal oxidases, a cytochrome $a_{3}$ oxidase (PPA701/ 702) and a cytochrome d oxidase (PPA173-176), and a $\mathrm{F}_{0} \mathrm{~F}_{1}$-type adenosine triphosphate synthase (PPA1238-1245). All genes of the EmbdenMeyerhof pathway, the pentose phosphate pathway, and the tricarboxylic acid cycle are present. Under anaerobic conditions, strain KPA171202 can grow on several substrates such as glucose, ribose, fructose, mannitol, trehalose, mannose, $\mathrm{N}$-acetylglucosamine, erythritol, and glycerol (11). In addition, several amino acid degrading pathways, similar to those of fermentative organisms, are present. Fermentative products are short-chain fatty acids, in particular propionic acid (11), whose production from pyruvate and methylmalonyl-coenzyme $(\mathrm{CoA})$ is initialized by the methylmalonyl-CoA carboxyltransferase (PPA2005-2008). In addition to fermentative energy conservation, $P$. acnes possesses systems involved in anaerobic respiration such as nitrate reductase (PPA507-511), dimethyl sulfoxide reductase (PPA515-517), sn-glycerol-3phosphate dehydrogenase (PPA2248-2250), and fumarate reductase (PPA950-952 and PPA14371439). Factors that might be involved in the life-style switch related to oxygen availability, as well as further aspects of the biology and biochemistry of $P$. acnes, are presented in the supporting online text.

Numerous genes have been found that can degrade and use host-derived substances (Table 1 and fig. S3). It has been proposed that free fatty acids, produced by $P$. acnes lipase activity on sebum, assist bacterial adherence and colonization of the sebaceous follicle $(2,12)$. In 